\title{
Hybrid Service Compositions: When BPM meets Dynamic Case Management
}

\author{
Konstantinos Traganos and Paul Grefen \\ Eindhoven University of Technology, The Netherlands \\ School of Industrial Engineering \\ kontrag@gmail.com, p.w.p.j.grefen@tue.nl
}

\begin{abstract}
In organizations' efforts to achieve process efficiency and agility, disciplines like business process management and case management have been used widely. While the former is a process-driven discipline which routes processes through specific activities, the latter advances through events based on the case data, characterizing it as event-driven and data-driven. However, these two apparently dissimilar approaches can be combined with the common goal to offer flexible service compositions in a service-dominant context. This paper proposes a way to do so through a business-engineering framework for service-dominant business. The structured approach for business design and the subsequent proposed implementation with IT systems will enable organizations, for instance in financial services sector, to leverage service automation. A working prototype for service management is developed as a proof-of-concept demonstrating that the realization of such a mixed approach is practically feasible.
\end{abstract}

Keywords: Service Management, Service Compositions, Service-dominance, Business Process Management, Dynamic Case Management.

\section{Introduction}

Many business domains are currently transitioning towards a service-oriented business setting. Before the transition, the business value used to be in owning assets while in the new setting the business value is in using the services offered by these assets. Representative examples can be found in the goods logistics domain, in the entertainment industry and in the IT industry. In the personal mobility domain, a focus on providing cars (e.g. in lease constructs) is replaced by mobility services (for instance public transport card, flex offices, etc.) that enable users to arrive at the right place at the right time. This transition creates service-dominant business markets where their not-sophysical characteristics create a high level of dynamism. This places high demands on the agility of service providers operating in these markets.

A way to deal with this high level of dynamism is to not see the services delivered as monoliths that are completely produced in-house, but as flexible compositions of sub-services, part of which are produced in-house and part of which are produced by third parties in the market (which become partners for this reason). In other words, 
players in service-dominant markets typically engage into dynamic business networks in which parts of offered services can be delivered by business partners.

However, these providers find their agility heavily constrained by the IT platforms they use to deliver their services. This especially is problematic, as increasing dynamism in a market typically requires higher levels of efficiency in dealing with changes. These higher levels of efficiency require higher level of automation, which obviously are strongly dependent on the capabilities of the automated platforms available. Such automated platforms can be service management systems that facilitate the provisioning of services with the aim to achieve application and operational flexibility in a service-dominant world.

In this paper, we introduce a framework for service-dominant business design and focus mainly on service compositions as an agile way to cope with dynamism. The realization of these service compositions, depending on their characteristics, is done with the disciplines of Business Process Management (BPM) and Dynamic Case Management (DCM). While these two are different in their approach to compositions, their combination facilitates the implementation of a hybrid type of service compositions. Mainly, this combination is based on the fact that internal complexity requires structured business processes while customer-facing services require ad-hoc ones. The BPM and DCM disciplines together can support both complexity and customer orientation.

Regarding the related work, the essence of service compositions from a business point of view has already been identified in terms of service touch points and customer journeys [1], service encounters [2] and value constellation experiences [3]. Their support can be achieved with the business process management discipline, however, most of the approaches have been focused on how extensions [4], [5] or alternatives [6], [7] of WS-BPEL can provide automation of service compositions.

The lack of flexibility of workflow technologies has been addressed in [8] but does not refer to service compositions. The same goes for [9], where adaptive case management is presented as an extension to BPM 2.0 without discussing whether these two disciplines can work together.

We see therefore a need of an approach to support the business side of service compositions with both BPM and DCM characteristics. Our approach addresses this need by contributing a structured framework for hybrid BPM/DCM-oriented service composition. To show the feasibility of such a hybrid type of composition, we also present a prototype of a service management application in the financial services sector.

The rest of this paper is structured as follows. In Section 2, we briefly introduce $\mathrm{BASE} / \mathrm{X}^{1}$, a business engineering framework for service-dominant business, focusing on service compositions. In Section 3, we discuss the operationalization of service compositions, while in Section 4 we describe how BPM and DCM can provide automated support. Then, in Section 5, we present the prototype for service management and finally, we conclude the work in Section 6.

\footnotetext{
${ }^{1} \mathrm{BASE} / \mathrm{X}$ is the acronym for Business Agility through Service Engineering in a Cross-Organizational Setting.
} 


\section{The three faces of Service Compositions through BASE/X}

In the introduction, we have discussed the move from an asset-orientation to a serviceorientation: customers recognize that business value is not in owning assets, but in using the services offered by assets (which they do not need to own). Before this transition, business settings used to be centered on the delivery of products or stand-alone services [10]. After the transition, they will be centered on the provisioning of solutionoriented, integrated services to customers (either business organizations or individual consumers) [11]. Services may require the deployment of products, but these products become part of the delivery channel of services, not the focal point themselves. The emphasis shifts from the value of the individual product or service to the value of the use of the product or service in an integrated context - the so-called value-in-use [12].

This transition though has consequences for the very basic characteristics of doing business [13]. First, customers expect coherent solutions, not stand-alone solution fragments. Second, customer-driven requirements to solution-oriented services will evolve much faster than requirements to the underlying products. Thus, managing agility in service delivery will be a key factor in the market position of a service provider. Third, managing service complexity and business agility requires a tight integration between the structure of business strategy and models on the one hand and the structure of business operation and information management on the other hand.

Performing the transition to service-dominant business and managing its consequences is a formidable task for any non-trivial business organization. Taking a traditional top-down, business-strategy-to-operations approach will be too slow in the current fast pace of market developments. Taking a quick-win, opportunity-driven, bottom-up approach will result in isolated implementations and chaos in integration efforts. A visionary, industry-strength approach is required that is completely tuned to the service-dominant transition and that has the very basics of service business at its core. BASE/X is such an approach, extending the well-known traditional pyramid which has been used for decades to distinguish the levels strategy, tactics, operations in business decision making.

BASE/ $\mathrm{X}$ is a business engineering framework, a well-structured way to address the analysis and design of service-dominant business, i.e., business that puts service management at the forefront of its design and operation [13]. It covers the entire spectrum from high-level business strategy definition to business information system architecture design, including elements like business model conception, business service specification and business process modelling. We present here the main components of the framework, while more information can be found in the full documentation in [13].

\subsection{Business design in BASE/X}

Business design in BASE/ $\mathrm{X}$ is based on the observation that we need the distinction between business goals (the 'what' of business) and business operations (the 'how' of business) on the one hand and the distinction between the stable essence of an organization and its agile market offerings on the other hand. This leads to a model with four layers, as shown in Fig. 1. 

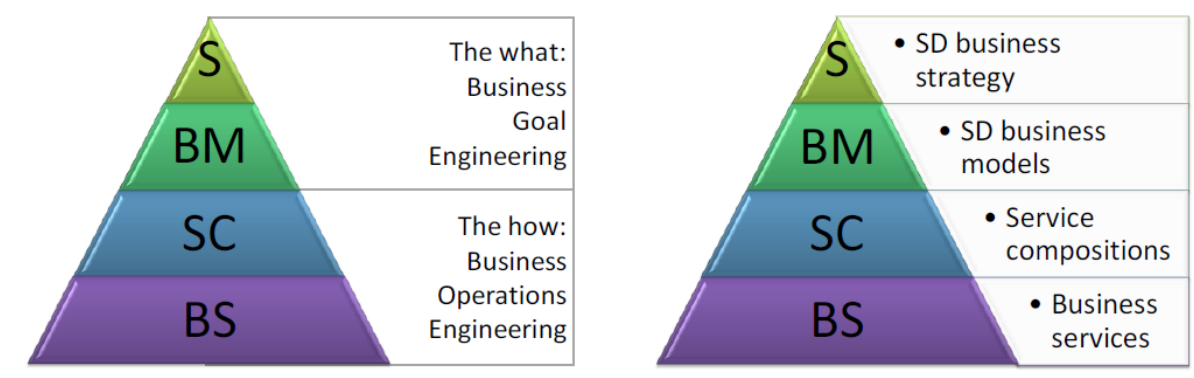

Fig. 1. BASE/X Business Pyramids

As shown in the left side of the figure, the top half of the pyramid covers business goal engineering. As shown in the right side of the figure, the top layer contains the service-dominant business strategy. This strategy describes the identity of an organization in a service-dominant market and is relatively stable over time. The second layer contains service-dominant business models. Each business model describes a market offering in the form of an integrated, solution-oriented complex service: they describe a concrete value-in-use. Business models follow fluid market dynamics and are agile.

The bottom half of the pyramid covers business operations engineering. The bottom layer contains business services, each of which contains a core service capability of the organization. These capabilities are related to the resources of the organization (covering both personnel and large-scale technical infrastructures). The third layer of the pyramid contains the service compositions. Each composition is a combination of business services to realize the service functionality required by a business model: they implement a concrete value-in-use. The combination includes business services from the organization's own set, but also business services of partner organizations in a business network. As service combinations follow business models, they are agile, meaning they revolve with their associated business models.

\subsection{Organization and IT platform design in BASE/X}

Organization design in BASE/X provides the organizational operationalization of the elements in the business pyramid discussed above. Organization design covers both automated organizational processes and manual processes. To obtain proper alignment between business and organization design, organization design follows the same four layers as business design. Proper co-engineering is achieved by mapping changes in a layer of the business pyramid to changes in the corresponding layer in the organization pyramid.

The design of the information technology platform in BASE/X provides the blueprint for the IT platforms that are required for the execution of the elements identified in the organization pyramid. For proper alignment, the platform design also follows the same four layers as the other two BASE/X pyramids.

The support of the business pyramid is shown in Fig. 2 below. 

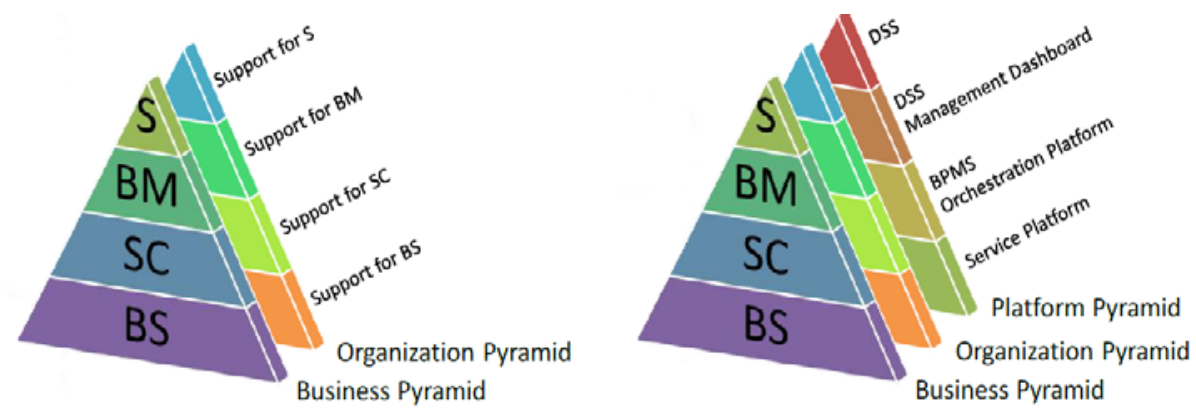

Fig. 2. Organization and Platform pyramids

\subsection{Service Composition layer in BASE/X}

Focusing on the third layer of the pyramids of Fig. 2, we can say that the Organization Pyramid offers support for service compositions, i.e., design and execution of operational business processes. These can have the form of specifications of automatically executable processes or service mash-ups.

In turn, the Platform pyramid provides the automated support for efficient integrated service delivery. It contains business process management systems or other forms of service orchestration platforms.

The cross-cutting of the three pyramids in the Service Composition layer of BASE/X, as shown in Fig. 3, is the focus of this paper.

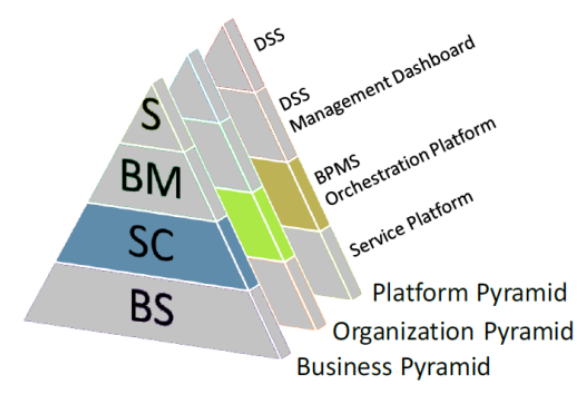

Fig. 3. The Service Composition layer

\section{Operationalization of Service Compositions}

The essence of service compositions is to make complex functionality available to a market by combining a set of simpler functionalities realized as services. The simpler business functionalities should be standardized within an organization (or even across its boundaries) as business services, such that these functionalities can be reused. 
Service compositions exist in two basic types: the process type and the mash-up type. Hybrid types also exist, by combining the characteristics of both basic types. In this section we present the characteristics of the basic types of service compositions which will be later mixed for a hybrid type.

\subsection{Service-based business processes}

The process type of service compositions is typically used for strictly sequenced business interactions in which the activities of multiple actors (business organizations and customers) need to be synchronized in time and information needs to be passed between these activities. Actors go through a well-defined sequence of steps: an explicit business process. A business process definition is required to make sure the individual actors remain well-synchronized in the execution of the composition. A definition is preferably described in a well-accepted business process specification language, such as BPMN.

In the process type, there is an explicitly managed (and possibly complex) state of a service delivery, where the management of the state is the responsibility (or even the added value) of the service orchestrator. Each defined service composition corresponds to a business process type. Each invocation of a service composition corresponds to a business process instance. The state of an individual service composition invocation is the state of that business process instance, which is typically managed automatically by a business process management system (third pyramid of BASE/X of Fig. 2), as we describe in Section 4.

Business processes are used to specify both customer-facing business processes, i.e. those who have meaning for a customer and change the state of the value-in-use defined by the business model and internal business processes, i.e. those who are encapsulated by a single customer-facing service and hence is invisible for the customer.

\subsection{Service mash-ups}

The mash-up type is typically used for free-form business interactions in which a single actor invokes the functionalities of a number of other actors. Individual services of a composition are invoked at a single actor's own will, i.e., without a sequence predefined by the service provider. The composition execution is terminated when the actor uses a termination service.

In the mash-up type, there is an implicitly managed (and usually simple) state of a service delivery, where the management of the state is the responsibility of the service consumer. Comparable to the situation with process-based service compositions, each defined service composition corresponds to a mash-up type. Each invocation of a service composition corresponds to a mash-up instance. A mash-up instance is very lightweight from a provider point of view, as there is no state management by the provider (but the provider may want to be aware that a mash-up instance is active, e.g. for CRM purposes). 
We consider service mash-ups as a suitable form of customer-facing business processes: those who have meaning for a customer and change the state of the value-inuse defined by the business model.

\section{$4 \quad$ Realization of Service Compositions}

According to the BASE/X framework, the Service Composition layer is supported by service orchestration platforms like business process management systems (BPMS) or service mash-up platforms in order to support the two kinds of business service composition that we have discussed in Section 1. In this section, we present the main characteristics of two disciplines, namely Business Process Management (BPM) and Dynamic Case Management (DCM), in order to show how they can be mixed and serve the role of realization of service compositions.

\subsection{BPM}

Business Process Management (BPM) is a field continuously growing, starting a few decades ago as a result of people's and organizations' efforts to redesign/reengineer boundary-crossing processes with the use of IT, aiming to improve customer services. Over these years, many definitions have been given for BPM. Examples are: "A customer-focused approach to the systematic management, measurement and improvement of all company processes through cross-functional teamwork and employee empowerment" [14], "Supporting business processes using methods, techniques, and software to design, enact, control, and analyze operational processes involving humans, organizations, applications, documents and other sources of information" [15]. From all these definitions, key observations can be made concluding in the following: BPM can be seen as a discipline that intersects knowledge from management and information technology and applies this to operational business processes. It covers all phases of these processes, from identification to discovery, diagnosis, planning, design, deployment, execution and control. Applying BPM in practice leads to consistency, lower operating costs, faster processes, enhanced flexibility and improved customer satisfaction translating into improved enterprise performance [16].

In this paper, we focus on BPM as a discipline to realize the concept of the Service Composition layer of the business pyramid of the BASE/X framework. This can be done by implementing a Business Process Management System (BPMS) which is an information system that coordinates automated business processes in such a way that all work is done at the right time by the right resource.

\subsection{DCM}

Case Management (or Case handling) is a paradigm for supporting flexible and knowledge-intensive business processes. Unlike workflow management, which uses predefined process control structures to determine what should be done during a workflow process, case management focuses on what can be done to achieve a business goal 
[17]. Case is the central notion, which can be seen as the coordination of multiple tasks (planned and unplanned) and associate content, towards a concrete objective. In case management, the knowledge worker in charge of a particular case is a cognitive worker who actively decides on how the goal of that case is reached, and the role of a case management system is assisting rather than guiding and restricting him in doing so.

The core features of case management are [17], [18]:

- avoid context tunneling by providing all information available (i.e., present the case as a whole rather than showing just bits and pieces),

- decide which activities are enabled on the basis of the information available rather than the activities already executed,

- separate work distribution from authorization and allow for additional types of roles, not just the execute role,

- allow workers to view and add/modify data before or after the corresponding activities have been executed (e.g., information can be registered the moment it becomes available).

In case management, the term "dynamic" refers to highly variable, unpredictable, loosely structured and subject to change cases and processes. It is related to flexibility and adaptability and the basic idea is to allow for changes at run-time, i.e. while work is being performed processes may be adapted [19].

A platform for service management with case management capabilities supports case workers to combine required knowledge, information and content in such a way that they either can solve the case or initiate the corresponding service(s), in compliance with rules, constraints and objectives.

\subsection{BPM and DCM into a hybrid system}

Traditional workflow management focus on the complete definition and control of structured, repeated processes while case management works on an ad hoc basis to manage dynamic, unstructured processes. BPM is a process-driven discipline which routes processes through specific activities. On the other hand, DCM advances through events based on the case data, characterizing it as event-driven and data-driven. Also, DCM is better used in processes where many exceptions and deviations appear, since attempting to capture all of these scenarios with traditional BPM [20], results in complex models that are hard to manage and maintain.

Based on the Mintzberg's Five Organizational Structures [21], we can say that BPM is best applied in Machine bureaucracy structures, where the standardization of work processes is the prime coordinating mechanism, while DCM is most suitable for Professional bureaucracy organizations where standardization of skills is the dominant mechanism.

The approach we suggest in this paper is to combine these two disciplines into a hybrid service management platform in order to exploit all possible capabilities of both approaches. BPM can be used for the automation of the existing standardized and optimized business processes of an organization, while DCM can be used for the whole handling of cases that are associated to services. 
With respect to the differentiation of business processes into customer-facing and internal ones, we consider BPM suitable for the orchestration of internal business processes, while DCM can be applied for the customer-facing business processes.

The hybrid type of service management can be achieved with a single suite where on the one hand services which are visible to the customer are handled with case management features and on the other hand internal workflows handle the execution and automation of building block services. Such a single platform is developed in a prototype of service management in the financial services sector, more specifically in the car leasing domain. The prototype is presented in the next section.

\section{Service Management Prototype}

A working prototype for service management was implemented to provide insight on how a hybrid service composition is realized. From a technical point of view, Service Oriented Architecture (SOA) techniques were applied in order to integrate services (mainly web services) from different information systems (internal or external to an organization). However, the interesting part is to show how a technical solution that combines both BPM and DCM capabilities is able to bridge business and technology in an agile way.

In the frames of a master thesis project [22], we applied our approach in an assetbased financial services company, and more specifically in its car leasing subsidiary. In this paper, we refer to this company using the fictitious name LeaseCar. After describing the service composition use case, its functionality and the underlying business process models, we present a few screenshots of the user interface.

\subsection{Driver Desk use case}

LeaseCar offers a single point of contact for all questions regarding lease vehicles, called Driver Desk. Drivers can turn to the Driver Desk, with literally any type of request, from the moment that their vehicle is on the road, up and until it is being returned. Through several communication channels such as telephone, e-mail or internet portal, they communicate with LeaseCar in order to ask a service or a combination of them. Driver Desk supports drivers on topics like Fines / Fuel cards / Fuel management / Repair, maintenance, tires (RMT) / Damages / Returning vehicles / Replacement cars / Ordering progress (occasionally) / General complaints handling.

These services can be presented in a mash-up form where the driver is free to opt, adhering though to any constraints related to these services. When a driver contacts Driver Desk, he can have an inquiry for one or more of the offered services. This inquiry is handled as a case with the help of a Dynamic Case Management dashboard. The actual execution of each service is implemented as a traditional workflow with BPM techniques. An overview of the Driver Desk use case is shown in Fig. 4. 

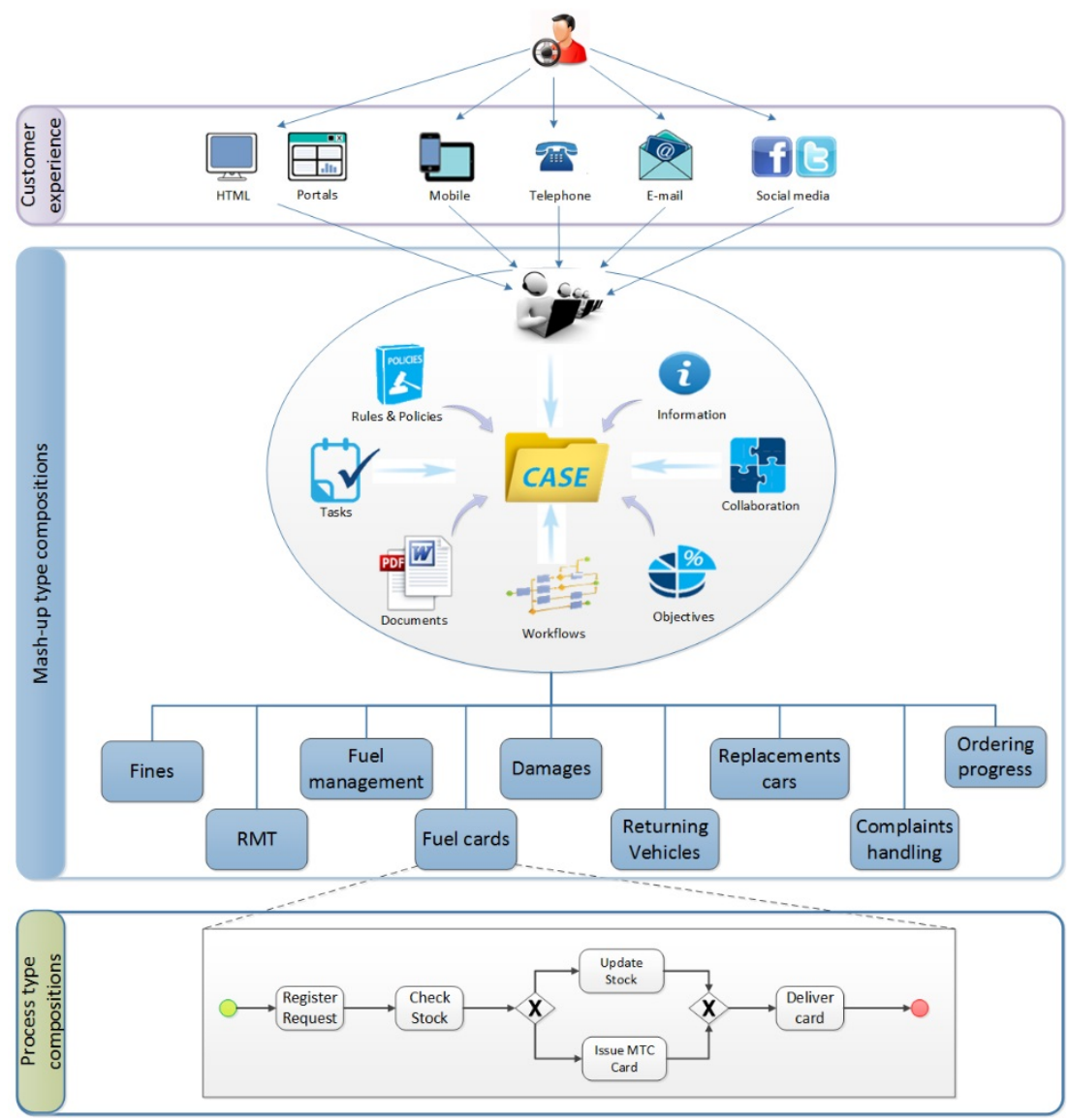

Fig. 4. Driver Desk overview

\subsection{Business processes definition}

The platform that facilitates our hybrid type of service compositions is based on the commercial Pega $7^{2}$ tool, which combines both BPM and DCM capabilities. A cloud environment was used in order not to jeopardize information systems of LeaseCar company.

Pega 7 uses a stage-based approach to first define a high-level overview of the whole process. For each stage, steps are defined which in turn need to be specified into more detailed business process model.

${ }^{2}$ http://www.pega.com/products/pega-7, retrieved July 12 ${ }^{\text {th }}, 2015$. 
Below, we present the internal business process (as a structured workflow) related to a corresponding service, the re-issue of a fuel card. The flow is rather straight-forward. We first have to cancel the existing fuel card and then issue a new one. Note here the existence of the "Cancel" sub-process which can be used also independently to run a card cancellation case. This flow is presented in Fig. 5.

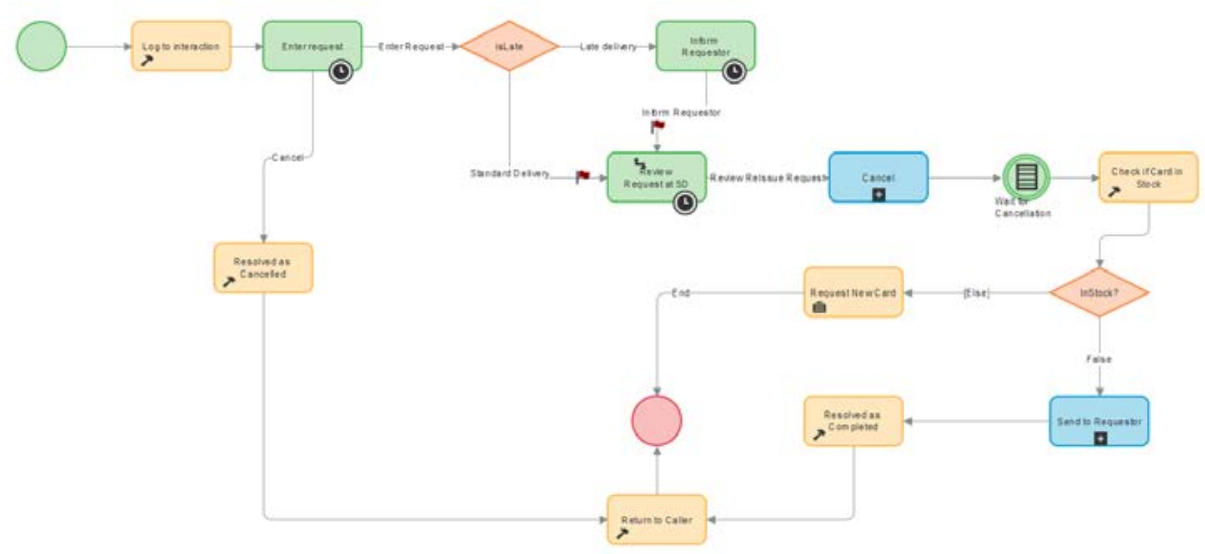

Fig. 5. Re-Issue Fuel Card process flow

The Case Management features of the prototype include the creation of cases (based on customers' inquiries), the association to them of any related documents or information that is necessary for the case worker to handle the cases and also statistics and metrics of cases and objectives. Moreover, task management features, like for instance who initiated a case and who is now working on it (through a complete case history), are present.

\subsection{User interface}

The main screens of the implemented prototype are presented here. More information can be found in [22].

The prototype is used by Driver Desk officers and the Driver Desk team leader who has more privileges (for instance, extra features for managing his team, reviewing statistics and reports, changing business rules). In case of an incoming call, they look up the driver based on his license plate. After retrieving his contact, all the right information for the selected driver is presented in the screen below. This is the main dashboard which is the DCM part as presented in the overview of Fig. 4. 


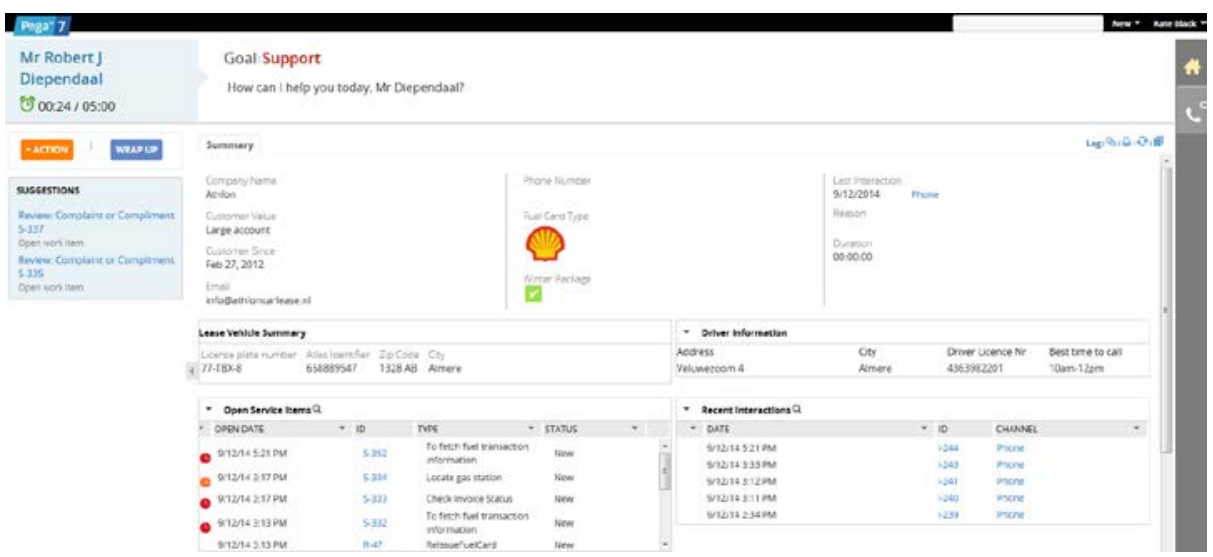

Fig. 6. Main screen for serving a driver

Information about driver's details, company's details in which he belongs, vehicle details and contract information are presented. A list with open cases for that specific driver and a list with past interactions are also available in order to allow the Driver Desk officer to serve the driver as efficiently as possible. After reviewing driver's data and getting his inquiry, a list of actions are available, corresponding to the services that Driver Desk can offer. This is available on the up left part of the dashboard and can be seen in Fig. 7.

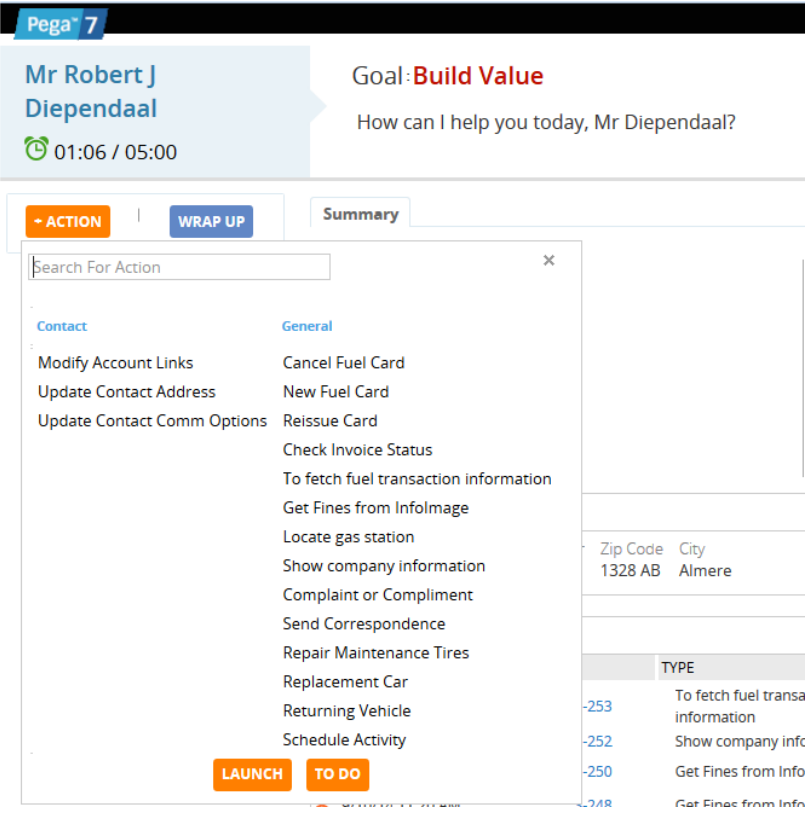

Fig. 7. List of supported actions - services 
Assuming for instance that the driver requests a list of fuel transactions on a predefined period, the corresponding service is executed as a number of workflow steps (not visible to the driver). As this is a service provided by an external partner, a web service is invoked to fetch the results as can been seen in Fig. 8.

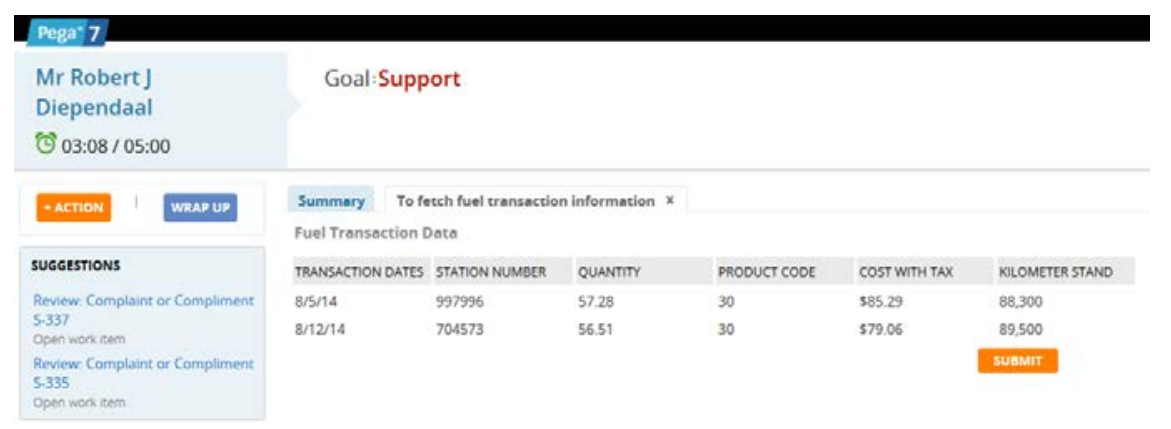

Fig. 8. Fuel Transactions results

\section{Conclusion}

Transitioning to a service-dominant world requires a major effort. Organizations need to engage into dynamic business networks with the aim to provide agile and flexible service compositions, as complete solutions to customer's problems. A well-structured framework for managing the complexity of service-dominant business is required. $\mathrm{BASE} / \mathrm{X}$ is such an approach, consisting both of a conceptual and a tooling aspect for analysis and design.

The part of the BASE/X that we focus on our paper is the realization of service compositions, which is supported by automated service management systems. Business Process Management and Dynamic Case Management concepts and tooling, are already available to support the offering of service compositions. But since these two disciplines have inherently different characteristics, our approach is to combine them in such a way that capabilities of both are exploited. Thus, our contribution is both how to mix the two disciplines and also how to design such a mix based on a businessengineering framework.

However, this paper does not touch upon all aspects of BPM and DCM cycles. For instance, further research is needed on notations that can facilitate the modeling of the mixed service compositions.

To demonstrate the feasibility and usability of our approach, a prototype application for service management was built for the car leasing domain. A dashboard that handles drivers' inquiries on their lease cars is used for DCM purposes. On the other hand, BPM techniques are used for the invocation of services that are not visible to the customer. The combination of these two approaches offers the realization of service compositions, in accordance to BASE/X third layer of Fig. 3.

The prototype received positive feedback from professionals (enterprise architects and team managers who were involved in the project and could use such a tool) through 
discussions, as being suitable to facilitate flexible service compositions. Business people perceived it as an agile way to integrate various services as part of service compositions and make easily changes on business rules. To demonstrate more general applicability of our approach though, it has to be applied in other domains, like for example in healthcare, where the separation of business process types may not be so clear to allow for a hybrid type of service compositions.

\section{Acknowledgements}

Thanks go to the professionals of LeaseCar company who provided the right support to apply our approach and to the Pega experts for undertaking the implementation part while we focused on the design and requirement analysis of the case study.

\section{References}

1. Zomerdijk L., Voss C.: Service Design for Experience-Centric Services. Journal of Service Research; Vol. 13, No. 1, pp. 67-82 (2009)

2. Bitner M., Brown S., Meuter M.: Technology Infusion in Service Encounters. Journal of the Academy of Marketing Science, Vol. 28, Nr. 1, pp. 138-149 (2000)

3. Patrício L., Fisk R., João Falcão e Cunha, Cons L.: Multilevel Service Design: From Customer Value Constellation to Service Experience Blueprinting. Journal of Service Research, Vol. 14, No. 2, pp. 180-200 (2001)

4. Ezenwoye O., Sadjadi S.M.: TRAP/BPEL: A Framework for Dynamic Adaptation of Composite Services. In: Proceedings of The International Conference on Web Information Systems and Technologies, Barcelona, Spain (2007)

5. Wu Y., Doshi P.: Making BPEL Flexible - Adapting in the Context of Coordination Constraints Using WS-BPEL. In: International Conference on Services Computing vol. 1, pp. 423-430 (2008)

6. Alexopoulou N., Nikolaidou M., Chamodrakas Y., Martakos D.: Enabling Onthe-Fly Business Process Composition through an Event-Based Approach. In: Proceedings of the Proceedings of the 41st Annual International Conference on System Sciences, pp. 379-389, Hawaii (2008)

7. Vanderfeesten I., Reijers H, Van der Aalst W.: Product Based Workflow Support: Dynamic Workflow Execution. In: Advanced Information Systems Engineering, pp. 571-57 (2008)

8. Van der Aalst W. M., Adams M., Hofstede A. H., Pesic M., Schonenberg H.: Flexibility as a Service. In: DASFAA 2009 Workshops, LNCS 5667 (2009)

9. Herrmann C., Kurz M.: Adaptive Case Management: Supporting Knowledge Intensive Processes with IT. In: S-BPM ONE 2011, CCIS 213 (2011)

10. Lusch R. F., Vargo S. L.: The Service-Dominant Mindset. In: Service Science, Management and Engineering Education for the 21st Century (2008) 
11. Ostrom A.L. et al.: Moving Forward and Making a Difference: Research Priorities for the Science of Service. In: J. Serv. Res. 13 (2010)

12. Lusch R. F.: Service-dominant logic: reactions, reflections and refinements. In: Mark. Theory (2006)

13. Grefen P., Lüftenegger E., Van der Linden E., Weisleder C.: BASE/X Business Agility through Cross-Organizational Service Engineering. Eindhoven University of Technology (2014)

14. Lee R. G., Dale B. G.: Business process management: a review and evaluation. Business Process Management Journal, Vol. 4 Iss: 3, pp. 214-225 (1998)

15. Van der Aalst W. M., ter Hofstede A. H., Wesk M.: Business Process Management: A Survey. In: International Conference on Business Process Management (2003)

16. Hammer M.: What is Business Process Management (2010)

17. Van der Aalst W. M., Weske M., Grünbauer D.: Case Handling: A New Paradigm for Business Process Support. Data and Knowledge Engineering, vol. 53, no. (2), pp. 129-162 (2005)

18. Van der Aalst W. M., Berens P. J.: Beyond Workflow Management: ProductDriven Case Handling. In: S. Ellis, T. Rodden, and I. Zigurs, editors, International ACM SIGGROUP Conference on Supporting Group Work, New York (2001)

19. Vanderfeesten I., Reijers H. A., Van der Aalst W. M.: Product Based Workflow Design with Case Handling Systems (2007)

20. Strong D. M., Miller S. M.: Exceptions and exception handling in computerized information processes. ACM Transactions on Information Systems, vol. 13, no. (2), pp. 206-233 (1995)

21. Lunenbrug F.C.: Organizational Structure: Mintzberg's Framework. International Journal of Scholarly, Academic, Intellectual Diversity, vol. 14, no. 1 (2012)

22. Traganos K.: Designing a Standard Architecture for Service Management based on the BASE/X framework. Eindhoven, The Netherlands (2014) 